\title{
The information technology knowledge infrastructure and research in South Asia
}

\author{
Khushboo Singhal, Sumit Kumar Banshal, Ashraf Uddin, Vivek Kumar Singh* \\ Department of Computer Science, South Asian University, New Delhi, India
}

\begin{abstract}
The South Asian region habitat about $17 \%$ of the world population and it is very important that we ensure development and prosperity of the citizens in the region for a developed and prosperous world. Information technology (IT) is considered as the technology of the modern world, one which has virtually become necessary for economic and scientific development of a nation. IT sector now plays a very important role in all spheres of life and has a measurable impact on the development trajectory of a country. The South Asian countries, despite lagging behind in Science and Technology sector development during the second half of the $20^{\text {th }}$ century, made noticeable progress in the IT sector in the recent past. IT has gradually become one of the largest services sector contributors to economies of the region and one of the major employment providers. However, at the same time, it is also true that the region lacs the effort toward the development of original hardware and software products and services. Most of the products (both hardware and software) are being designed, conceptualized, and manufactured elsewhere, and the South Asian region is merely contributing to the operational part by virtue of utilizing abundant manpower. It is in this context that we have tried to measure the level of preparedness of the core strength of the IT knowledge sector and the level of research efforts in this sector towards creating original algorithms, products, and services. The paper explores and measures the IT knowledge infrastructure and the research competence of South Asian countries and provides a detailed analysis of the scenario.
\end{abstract}

Keywords: Digital technologies, information technology, research and development, South Asia, Technology and South Asia

\section{INTRODUCTION}

Information technology (IT) is a generalized terminology, which encompasses creation, manipulation, access, processing, presenting, protecting, and sharing information using different kind of hardware and software systems. IT involves systems based mainly on computers and communication technologies. It includes software programs like databases, spreadsheets, image editing software,

*Address for correspondence:

E-mail: vivekks12@gmail.com

\begin{tabular}{|c|c|}
\hline \multicolumn{2}{|c|}{ Access this article online } \\
\hline Quick Response Code: & \\
\hline \multirow{2}{*}{ 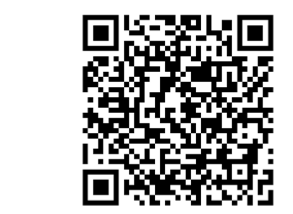 } & $\begin{array}{l}\text { Website: } \\
\text { www.jscires.org }\end{array}$ \\
\hline & $\begin{array}{l}\text { DOI: } \\
10.4103 / 2320-0057.153578\end{array}$ \\
\hline
\end{tabular}

assistive technologies etc.; and communication systems like internet, E-mail, video conferencing, etc., During the last two decades, it has become the backbone of development in other sectors as well. It would not be inappropriate to say that IT is "the technology" of the day, a ubiquitous technology which has reduced distances and information barriers between people in different parts of the world. Large multinational companies and business empires are now able to expand and take their operations to different parts of the world, largely due to the IT revolution. IT infrastructure is now a key component of economic preparedness and development of a country. Unless a country is substantially prepared and institutes the required IT infrastructure, it would not be able to attract foreign investments and operations of multinational corporations, thereby losing on revenue and employment opportunities. Perhaps this is the understanding that made South Asian countries to start investing in the infrastructure development in the sector and to produce trained manpower. 
South Asian countries (we refer to the eight SAARC countries - Afghanistan, Bangladesh, Bhutan, India, Maldives, Nepal, Pakistan, and Sri Lanka) have improved substantially on their IT preparedness over the years and in fact some countries in the region such as India are in fact now a major center for IT development activities for the whole world. IT is now a major employment provider and biggest services sector revenue contributor. However, despite the noticeable progress, the region still lacks efforts toward the development of original products and services. While South Asian countries continue to be a major place and source for development of customized software and back-end operations, they lag behind in development of original generic software products and services. Most of the generic software continue to be created at development centers in the developed countries (ironically with participation of many South Asian nationals). One major reason for this is the high level of research competence in computer science (CS) of the developed countries. While South Asia has adopted an alien science/technology, it continues to remain a second-class citizen when it comes to original research output in the IT sector. It is in this context that we have tried to measure the research competence and potential of South Asian region in IT and assess the research preparedness, in general. We have adopted a multi-dimensional approach, by collecting and analyzing relevant data from various viewpoints. A standard scientometric methodology forms the core of the approach and allows us to evaluate and compare the IT research competence of the South Asian region vis-à-vis the developed world.

The rest of the paper is organized as follows - The section 2 gives an overview of the IT sector and general preparedness levels of the South Asian countries. Section 3 describes the source and statistics of the scientometric data collected for analysis. Section 4 presents detailed outputs of the scientometric-based empirical analysis. It includes various parameters ranging from research output share, collaboration patterns, usefulness and productivity assessment, etc., Section 5 presents a relevant discussion of the analytical outcomes.

\section{THE INFORMATION TECHNOLOGY KNOWLEDGE INFRASTRUCTURE OVERVIEW}

The last two decades have seen the evolution of "E-" systems and services in the region. This transformation is possible with underlying IT infrastructure and connectivity. We thought to first have a look at the relevant indicators of research and development expenditure, IT readiness etc., before moving to a detailed empirical analysis of research output data. Table 1 presents values for some of the relevant indicators for South Asian region such as expenditure on higher education, expenditure in research and development and researchers per million. These indicators give us a contextual overview of the overall higher education and research and development sector. The table also shows values for the top ranking countries in the world to have a comparative understanding of the values. As we see from the table, the South Asian countries have relatively low values on most of the indicators. The school enrollment for tertiary education indicator value is highest for India (23.27\%) among the countries in the South Asian region, though it is substantially lower than the top-ranking country in the world $(113.9 \%)$. The enrollment values in the table refer to gross enrollment and also include students from other countries enrolling in tertiary education program of a given country. In terms of the government investment in education sector, Nepal has the highest position with \% of GDP value on higher education as $4.72 \%$ and $\%$ of government expenditure on higher education as $22.71 \%$. The data collected from South Asian Countries shows that the main concern is the low expenditure on research and development activities, which stands below 1\% of GDP value for all South Asian countries. Similarly, in terms of researchers per million people, the values are much lower than the top ranking countries. For example, India with the region highest value of 160 researchers per million capita is far below the world best value of 7,717 researchers per million capita. Despite having huge population and potential manpower for research and development activities, the region has not been able to tap the potential. Low higher education enrollment and low expenditure on the sector are two primary reasons for this. Another related information is about the number and nature of higher education institutions in the region. Table 2 presents statistics of number and type of institutions of higher learning in the region. It is these institutions which account for major research output, with very few research labs existing in the region. The nongovernment expenditure in higher education sector is increasing at a rapid rate in some of the South Asian countries, such as Bangladesh and India.

After having a glance at the overall contextual environment, we thought of having a look at the broader IT infrastructure and IT readiness of the South Asian countries. We first had a look at the IDI (ICT Development Index) values for the region (http://www.itu.int/dms_pub/itu-d/opb/ 
Table 1: Relevant indicators for South Asian Countries

\begin{tabular}{|c|c|c|c|c|c|c|c|c|c|c|}
\hline Indicator & Year & $\begin{array}{l}\text { World } \\
\text { top value }\end{array}$ & Afghanistan & Bangladesh & Bhutan & India & Maldives & Nepal & Pakistan & Sri Lanka \\
\hline $\begin{array}{l}\text { School enrollment, tertiary } \\
(\% \text { gross })^{a}\end{array}$ & 2011 & 113.9 & 3.74 & 13.15 & 8.74 & 23.27 & 11.33 & 14.49 & 8.31 & 15.02 \\
\hline $\begin{array}{l}\text { Public spending on education, total } \\
(\% \text { of GDP })^{b}\end{array}$ & 2011 & 9.41 & NA & 2.23 (2009) & 4.65 & 3.43 & 6.82 & $4.72(2010)$ & 2.22 & 1.99 \\
\hline $\begin{array}{l}\text { Public spending on education, total } \\
(\% \text { of government expenditure })^{c}\end{array}$ & 2011 & 33.1 & NA & $13.84(2009)$ & 11.29 & 11.28 & 15.76 & $22.72(2010)$ & 10.05 & 9.32 \\
\hline $\begin{array}{l}\text { Researchers in R and D } \\
(\text { per million people })^{d}\end{array}$ & 2010 & 7717 & NA & NA & NA & 160 & NA & 0.30 & 148.85 & 0.16 \\
\hline $\begin{array}{l}\text { Research and development } \\
\text { expenditure ( } \% \text { of GDP) }\end{array}$ & 2011 & 4.04 & NA & NA & NA & 0.81 & NA & $0.30(2010)$ & 0.33 & $0.16(2010)$ \\
\hline
\end{tabular}

ahttp://data.worldbank.org/indicator/SE.TER.ENRR, ${ }^{\circ h t t p: / / d a t a . w o r l d b a n k . o r g / i n d i c a t o r / S E . X P D . T O T L . G D . Z S, ~ c h t t p: / / d a t a . w o r l d b a n k . o r g / i n d i c a t o r / ~}$ SE.XPD.TOTL.GB.ZS, "http://data.worldbank.org/indicator/SE.XPD.TOTL.GD.ZS, ehttp://data.worldbank.org/indicator/SE.XPD.TOTL.GB.ZS. NA $=$ Not available, GDP $=$ Gross Domestic Product

\section{Table 2: Number and type of higher education institutions in South Asia}

\begin{tabular}{lccc}
\hline Country & Public sector institutions & Private institutions & Total \\
\hline Afghanistan $^{\mathrm{a}}$ & 29 & 43 & 72 \\
Bangladesh $^{\mathrm{b}}$ & 32 & 54 & 86 \\
Bhutan $^{\mathrm{c}}$ & 1 & 0 & 1 \\
India $^{\mathrm{d}}$ & 495 & 192 & 687 \\
Maldives $^{\mathrm{e}}$ & 1 & 0 & 1 \\
Nepalf $^{\mathrm{f}}$ & 8 & 1 & 9 \\
Pakistan $^{\mathrm{g}}$ & 127 & 81 & 208 \\
Sri Lanka $^{\mathrm{h}}$ & 19 & 26 & 45 \\
\hline
\end{tabular}

ahttp://www.aisa.org.af/study/Comprehensive\%20study\%200f\%20 Higher\%20Education\%20in\%20 Afghanistan_2.pdf, bhttp://en.wikipedia. org/wiki/List of universities in Bangladesh, chttp://en.wikipedia.org/ wiki/List_of_universities_in_Bhutan, dhttp://en.wikipedia.org/wiki/ List of universities in_India, ehttp://en.wikipedia.org/wiki/Education in the_Maldives\#Higher_education, fhttp://en.wikipedia.org/wiki/ List of universities and colleges in Nepal, ghttp://en.wikipedia.org/ wiki/List of universities in_Pakistan, " ${ }^{-}$http://en.wikipedia.org/wiki/ List_of_universities_in_Sri_Lanka

ind/D-IND-ICTOI-2012-SUM-PDF-E.pdf). The IDI benchmark is computed by United Nations International Telecommunication Union, and is composed of 11 indicators grouped in three clusters: Access, use, and skill, with the broader aim to measure the net development of IT (http://en.wikipedia.org/wiki/ICT_Development_ Index). The access sub-index includes five infrastructure and access indicators (fixed-telephony, mobile telephony, international Internet bandwidth, households with computers, and households with internet). The use sub-index includes three ICT intensity and usage indicators (Internet users, fixed (wired)-broadband, and mobile broadband). The skills sub-index includes three proxy indicators (adult literacy, gross secondary enrollment and gross tertiary enrollment). The values are assigned on a scale of $0-10$, with Qatar having the lowest value of 6.24 and South Korea having the highest value of 8.56 (http://www.itu.int/dms_pub/itu-d/opb/
ind/D-IND-ICTOI-2012-SUM-PDF-E.pdf). We show the IDI values for the South Asian region and the five leading countries of the world in Table 3. As we see, Maldives has a leading position among South Asian countries, though with the world rank of 72 . India, the modern day IT hub, ranks at $119^{\text {th }}$ place. Similarly, the other South Asian countries also rank above $100^{\text {th }}$ position. These values show the relatively poor state of affairs of ICT Readiness of the South Asian countries and suggest that substantial effort needs to be put in for improving the infrastructure and preparedness of the sector and to achieve IT-based economic growth.

We have also tried to explore the connectivity infrastructure and the penetration levels for the South Asian countries. First, we obtained statistics about Internet and Social penetration for various regions of the world. Figure 1 shows internet penetration values obtained from we are social (http://wearesocial.sg/) for different world regions. We observe that the developed regions/countries that is, North America, Western Europe, and Oceania have internet penetration of $81 \%, 78 \%$, and $63 \%$, respectively; whereas the South Asian region has only 12\% internet penetration rate. This value is very low as compared to the developed region. Similarly, we also looked at Social media penetration rates and found that for South Asia, the penetration rate is about $7 \%$. Figure 2 shows the social media penetration rates for various regions of the world. The values for North America, Western Europe, and Oceania are $56 \%, 44 \%$, and $44 \%$, respectively. We have also collected statistics of Internet Users and penetration rates for all the eight South Asian countries. Table 4 shows the values of these parameters. As we can see from the table, the Internet penetration rates for all the South Asian countries are very low (ranging from 5\% in Afghanistan and Bangladesh each to about 35\% in Maldives). This is substantially lower than the Internet penetration rates of 


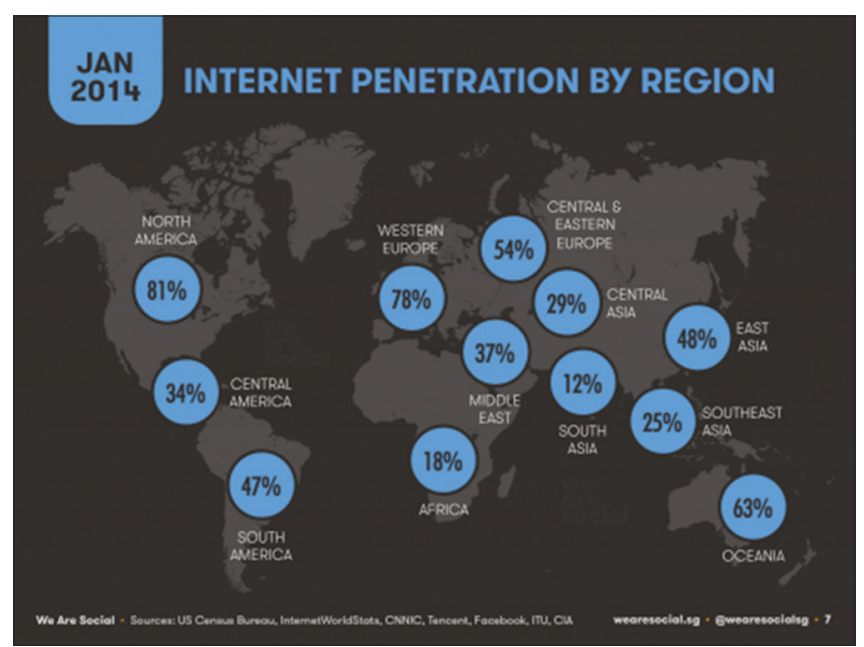

Figure 1: Worldwide internet penetration

Table 3: IDI Rankings 2011 (World top-5 and the South Asian Countries)

\begin{tabular}{lc}
\hline Country & World rank \\
\hline Korea (republic) & 1 \\
Sweden & 2 \\
Denmark & 3 \\
Iceland & 4 \\
Finland & 5 \\
Maldives & 72 \\
Sri Lanka & 105 \\
Bhutan & 118 \\
India & 119 \\
Pakistan & 127 \\
Nepal & 137 \\
Afghanistan & N/A \\
Bangladesh & N/A \\
\hline Souce: htt://MW.tuint/dspub/itu-d/opb/indD-IND-ICTOI-2012-
\end{tabular}

Source: http://www.itu.int/dms_pub/itu-d/opb/ind/D-IND-ICTOI-2012SUM-PDF-E.pdf. NA= Not available, IDI=ICT Development Index, ICT = Information and communication technology

developed countries. All these parameters establish the broader contextual picture for the empirical analysis and discussion presented in next few sections of the paper.

\section{SCIENTOMETRIC DATA COLLECTION}

To do systematic analysis of research competence of the South Asian countries in IT, we have collected scientometric data of research outputs from these countries, from the Web of Science (WoS) index. The data collection corresponds to the period of 25 years, from 1989 to 2013. This is the period of major growth in IT sector activities of the region. A total of 15,841 research papers from this region are indexed in WoS, for the given period. We collected full records for all these publications. The entire data collection is processed programmatically. There were duplicate entries, which

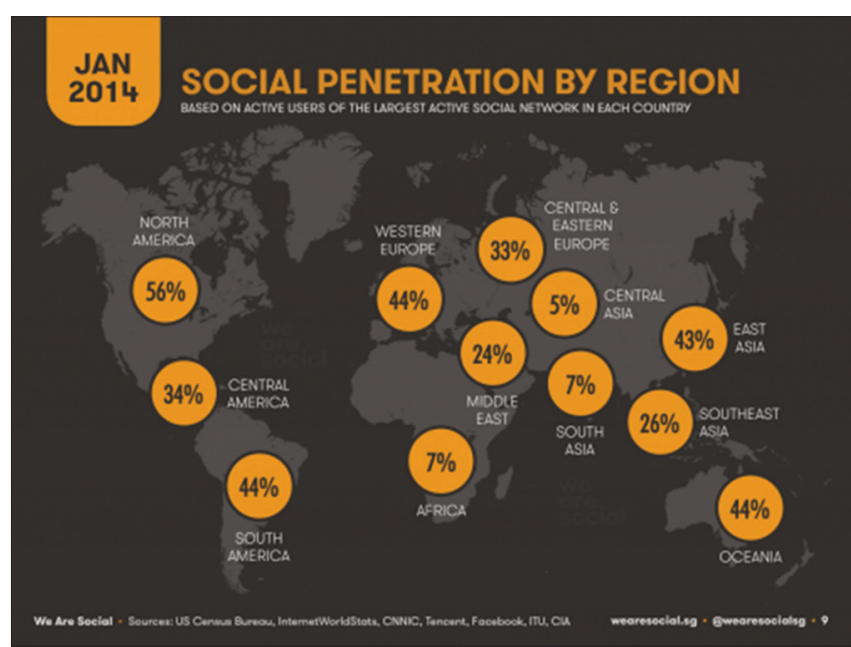

Figure 2: Social penetration worldwide by region

were removed, leaving us with 15,810 unique publication records. Each publication record contains 59 fields, such as authors, affiliation, title, publication year, abstract, etc., Of the total publication records collected, India accounts for 14,567 records, about $91.95 \%$ of total research output from the region. India, the largest country in the region in terms of geographical size and population, has thus a major share. We have plotted the geographical location of the top IT research institutions of South Asian region on an interactive map in Figure 3. This tagged map is generated using an online tool (http: / / www.gpsvisualizer. $\mathrm{com} /$ ) and can be accessed for interactive viewing from our web page (http://www.viveksingh.in/publications/ jsr/map.html). Our data collection thus corresponds to the research work in IT carried out in the region and is a measure of original research and development effort in IT.

\section{EMPIRICAL ANALYSIS}

The IT research output data collected contained 59 fields for each record. The data correspond to publications indexed in WoS and as such can be regarded as the most qualitative research output in IT from the region. The large data called for a computational analysis and hence we performed a detailed programmatic analysis of the data collected. The analysis is done on various parameters of interest ranging from total research output, authorship and collaboration patterns, productivity of research output, etc. First of all, we measure the total research output of the South Asian region and compute per capita and per GDP outputs of all the South Asian countries, and correlated them with the world top output producing countries. Table 5 shows the statistics of the total IT research output of South Asian countries and few top output producing 
Table 4: Internet penetration and other statistics for South Asian Countries

\begin{tabular}{lccccc}
\hline Country & Population & Number of internet users & Internet penetration (\%) & Facebook users & Broadband speeds (Mbps) \\
\hline Afghanistan & $30,419,928$ & $1,520,996$ & 5.0 & 384,220 & 1.13 \\
Bangladesh & $161,083,804$ & $8,054,190$ & 5.0 & $3,352,680$ & 2.73 \\
Bhutan & 716,896 & 150,548 & 21.0 & 82,040 & 4.53 \\
India & $1,205,073,612$ & $137,000,000$ & 11.4 & $62,713,680$ & 4.21 \\
Maldives & 394,451 & 136,760 & 34.7 & 136,760 & 3.21 \\
Nepal & $29,890,686$ & $2,690,162$ & 9.0 & $1,940,820$ & 4.63 \\
Pakistan & $190,291,129$ & $29,128,970$ & 15.3 & $7,984,880$ & 2.31 \\
Sri Lanka & $21,481,334$ & $3,222,200$ & 15.0 & $1,515,720$ & $\mathrm{NA}$ \\
\hline
\end{tabular}

Source: http://www.internetworldstats.com/stats3.htm\#asia. NA= Not available

Table 5: Total CS research output, world top and South Asian Countries (1989-2013)

\begin{tabular}{|c|c|c|c|c|c|c|}
\hline Rank & Country & $\begin{array}{c}\text { Number of publications, } \\
1989-2013\end{array}$ & $\begin{array}{l}\text { Population a } 2013 \\
\text { (million) }\end{array}$ & $\begin{array}{l}\text { GDP (PPP) (2013) } \\
\text { US \$ (billion) }\end{array}$ & $\begin{array}{l}\text { Publication } \\
\text { per capita }\end{array}$ & $\begin{array}{l}\text { Publication } \\
\text { per GDP }\end{array}$ \\
\hline 1 & United States & 236,062 & 316.44 & 16,720 & 745.99 & 14.12 \\
\hline 2 & China & 64,580 & 1349.59 & 13,370 & 47.85 & 4.83 \\
\hline 3 & United Kingdom & 50,843 & 53.01 & 2320.104 & 959.12 & 21.91 \\
\hline 4 & Germany & 48,956 & 81.15 & 3227 & 603.28 & 15.17 \\
\hline 14 & India & 14,567 & 1220.8 & 4962 & 11.93 & 2.94 \\
\hline 53 & Pakistan & 913 & 193.24 & 574.1 & 4.72 & 1.59 \\
\hline 77 & Bangladesh & 268 & 163.65 & 311 & 1.64 & 0.86 \\
\hline 92 & Sri Lanka & 70 & 21.68 & 128.4 & 3.23 & 0.55 \\
\hline 125 & Nepal & 20 & 30.43 & 41.22 & 0.66 & 0.49 \\
\hline 171 & Bhutan & 2 & 0.73 & 5.036 & 2.74 & 0.4 \\
\hline 191 & Afghanistan & 1 & 31.11 & 34.29 & 0.03 & 0.03 \\
\hline NA & Maldives & 0 & 0.39 & 3.106 & 0 & 0 \\
\hline
\end{tabular}

$\mathrm{NA}=$ Not available, $\mathrm{CS}=$ Computer science, $\mathrm{GDP}=$ Gross Domestic Product, $\mathrm{PPP}=$ Purchasing power parity

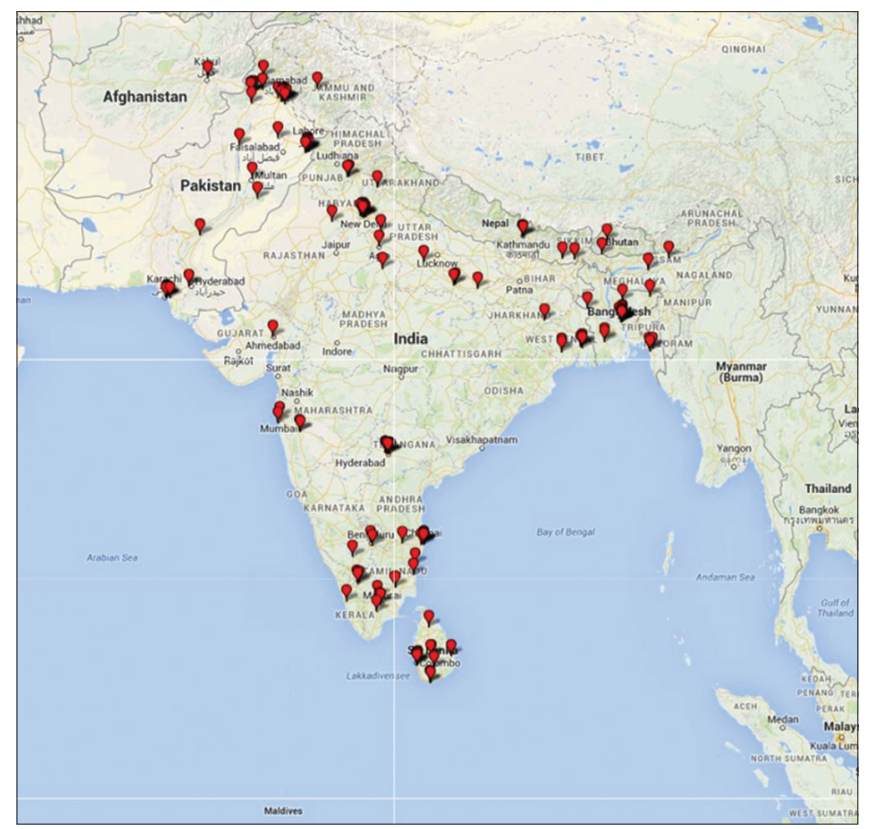

Figure 3: Geographical spread of South Asian Institutions on information technology research

countries. The table also includes statistics on population, GDP, and the computed values of research publications per capita and per GDP. As we can see from the table, United States has top rank in the total research output, whereas United Kingdom has the highest publication per capita. In contrast, among South Asian countries, India at $14^{\text {th }}$ rank worldwide, have 11.93 publications per capita and 2.94 publications per GDP. The values are pretty low in comparison to the leading countries. India is followed by Pakistan with $53^{\text {rd }}$ rank worldwide. Only one South Asian country figure in top 50 and only four countries figure among top 100 IT research producing countries worldwide. However, values of publications per capita and publications per GDP are pretty low for these countries. We also measured the proportionate contribution of all South Asian countries taken together to the total IT research output of the world. It is observed that South Asia's contribution to IT research worldwide for the 25 year period is only $2.02 \%$. Further, out of the total IT research output of the South Asian countries, India alone contributes $91.98 \%$, followed by Pakistan (5.73\%), Bangladesh (1.69\%), Bhutan (0.012\%), Nepal (0.13\%), Sri Lanka (0.44\%), and Afghanistan (0.006\%). No IT research output record is seen from Maldives (though Maldives 
has 81 publications-all disciplines taken together-indexed in $\mathrm{WoS})$.

The second important analytical outcome we obtained is about the relative strength of IT research in South Asian countries with respect to other disciplines. In Table 6, we show the total research output (all domains) of each of the eight South Asian countries and also the IT research output. The last column in the table depicts the percentage contribution of IT research to the total research output, for the given period, for all the eight South Asian countries. We observe that the overall percentage contribution of IT domain research to the total research of all the South Asian countries is quite low (approximate $2 \%$ max). The highest value is for India $(2.1 \%)$ and lowest for Afghanistan (0.25\%). The lower values of IT research output vis-à-vis other disciplines indicate an incongruence between the economic perspective of the IT and effort put in for original research and development in the sector.

The third parameter we thought to be of interest and value is the productivity level (measured as the impact) of the IT research work of South Asian countries. Citation is considered a relevant measure of productivity and effectiveness of research work. ${ }^{[1]}$ Those research outcomes which attract higher citations are considered more effective and productive. Citation counts also are an indirect measure of quality of research work. We have tried to measure the citation-based impact of IT research output from South Asian countries. For this, we compute Average Citation Per Paper (ACPP) and the ratio between cited versus un-cited research output. The "Z9" field of WoS data representing "total times cited count" is used to calculate total citations of a research publication. In order to compute ACPP value for a country, we divide total citations to all its output by the total output size. We plotted the values for 25 years in year-wise manner. Since, older papers have higher

\begin{tabular}{|c|c|c|c|}
\hline Country name & TP & TP in CS & CS as percentage of TP \\
\hline Afghanistan & 392 & 1 & 0.25 \\
\hline Bangladesh & 16,231 & 269 & 1.65 \\
\hline Bhutan & 269 & 2 & 0.74 \\
\hline India & 690,894 & 14,567 & 2.10 \\
\hline Maldives & 81 & 0 & 0 \\
\hline Nepal & 5239 & 20 & 0.38 \\
\hline Pakistan & 48,839 & 913 & 1.86 \\
\hline Sri Lanka & 7868 & 70 & 0.89 \\
\hline Total & 769,813 & 15,841 & 2.05 \\
\hline
\end{tabular}

$\mathrm{TP}=$ Total publications, $\mathrm{CS}=$ Computer science citation window and more likely to have higher citation count (due to the age bias), we computed a time adjusted ACPP value as well. This normalization has been done by dividing ACP $P$ values by its chronological distance from the publication year to the year 2013. In Figure 4, ACPP and time adjusted ACPP have been plotted on different axes and scales. The cited versus un-cited ratio for research outputs from South Asian countries is plotted in Figure 5. The values are plotted in 5-year blocks for better visibility. When we compared the average ACPP values for few developed countries with few countries in South Asian region, we observed that ACPP for the Indian and world top institutions are 4.39 and 8.56 , respectively. A similar result is shown in a recent work (Singh et al., 2015) ${ }^{[2]}$, which states that cited versus un-cited percentages for India and world top institutions in CS domain research are $44 \%$ and $59 \%$, respectively.

The fourth parameter of interest that we analyzed is the authorship and collaboration pattern in IT research work from South Asian countries. It is often said that collaboration attracts more researchers and hence increases citation for the paper as compared to a non-collaborated paper (Frenken et al., 2005). ${ }^{[3]}$ A collaborative research output could be of various types. It may involve collaboration between different researchers of the same institution or researchers from different institutions in a country. It may also involve collaboration between researchers from institutions in different countries, generally known as International Collaborative Papers (ICP). Co-authorship and collaboration patterns give an idea about the research environment and knowledge sharing patterns among researches. For our analysis, first we measured the co-authorship patterns for IT research output of the South

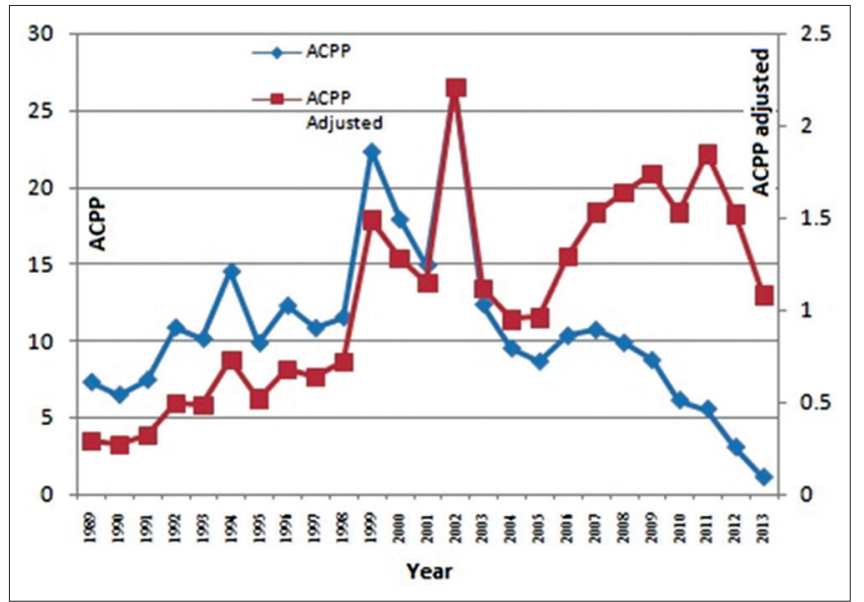

Figure 4: Average citation per paper and ACPP time adjusted plots 
Asian countries. Figure 6 plots year wise co-authorship pattern for South Asian IT research output (expressed in terms of percentage to total output). We observe that single authored paper percentage is decreasing, and the percentage of papers having more than three authors is increasing over the period of time. Thus, we have a favorable trend of research cooperation among researchers. We have also measured the total percentage of collaborated papers which are having at least two authors. Figure 7 shows that about $90 \%$ of the total IT research output from South Asian countries is collaborative. Further, among the collaborative papers, we tried to find out collaboration to the outside world and collaboration between researchers within the South Asian region. We observe that only about $1 \%$ of the ICP from South Asian region involve collaboration between authors/institutions within South Asian region whereas about $99 \%$ collaborative output is outside South Asian region, as shown in Figure 8. A similar recent work

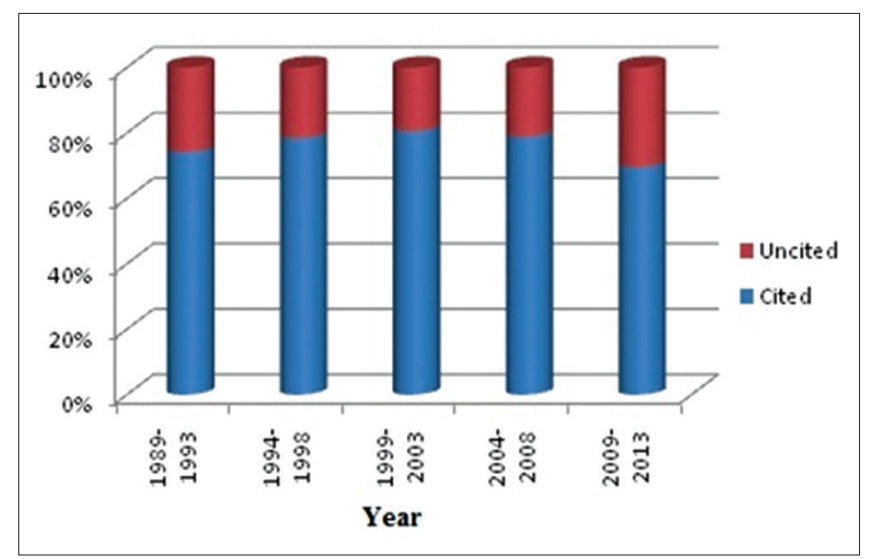

Figure 5: Cited versus un-cited information technology research output proportion in South Asia

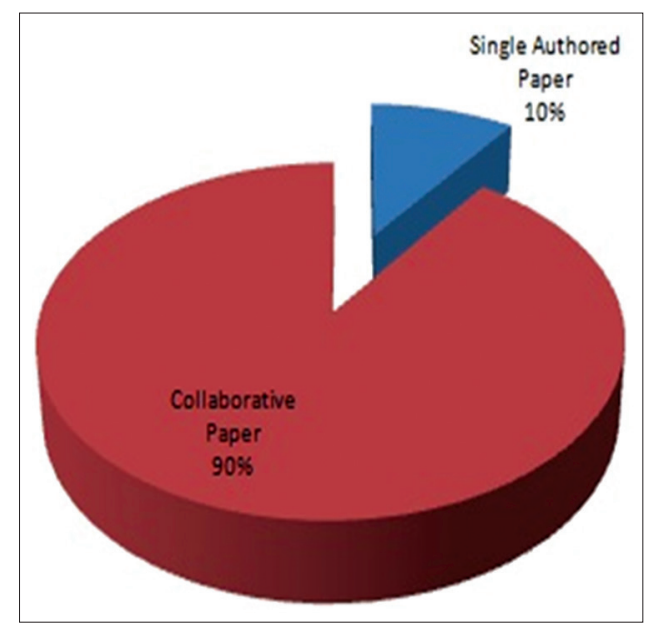

Figure 7: Information technology research authorship pattern in South Asia for India (Uddin and Singh, 2015) ${ }^{[4]}$ shows that $28 \%$ of the total output of world top institutions involve international collaboration, whereas only $17 \%$ papers from Indian top institutions are instances of ICP.

Looking at higher collaboration of the IT researchers in South Asia with countries outside the region, we tried to measure the actual amount of collaborated IT research for all the eight South Asian countries. We identified and plotted ICP, both within South Asia and outside South Asia. Since, the records do not contain explicit country information; the country affiliation of a research paper is derived from the "C1" field of the WoS record, which specifies "Author Address." Figure 9 shows collaboration network in IT research among South Asian countries and also with some other leading countries of the world. We

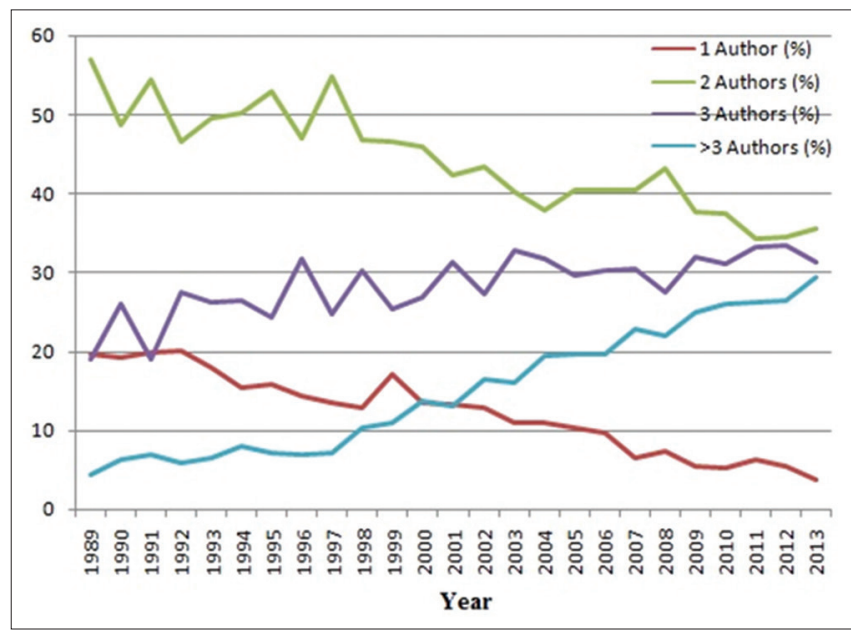

Figure 6: Information technology research co-authorship pattern in South Asia

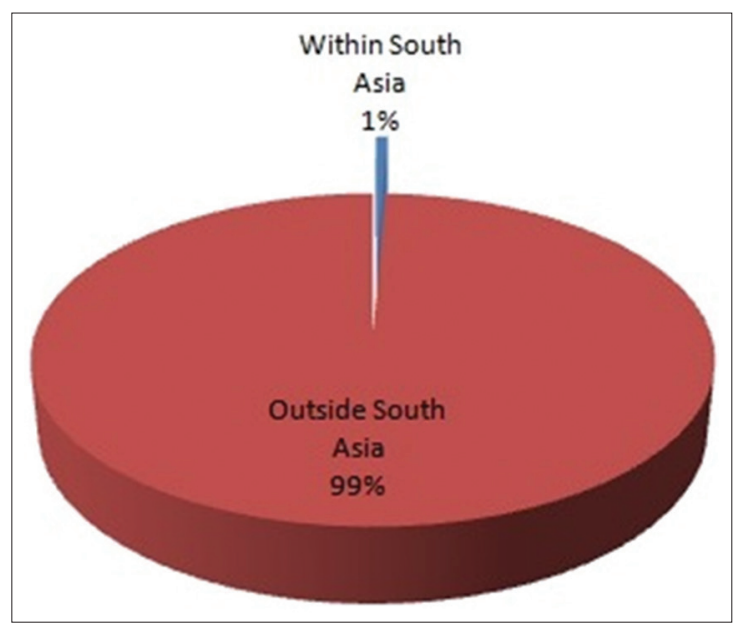

Figure 8: Collaboration pattern of South Asian region - within and outside 


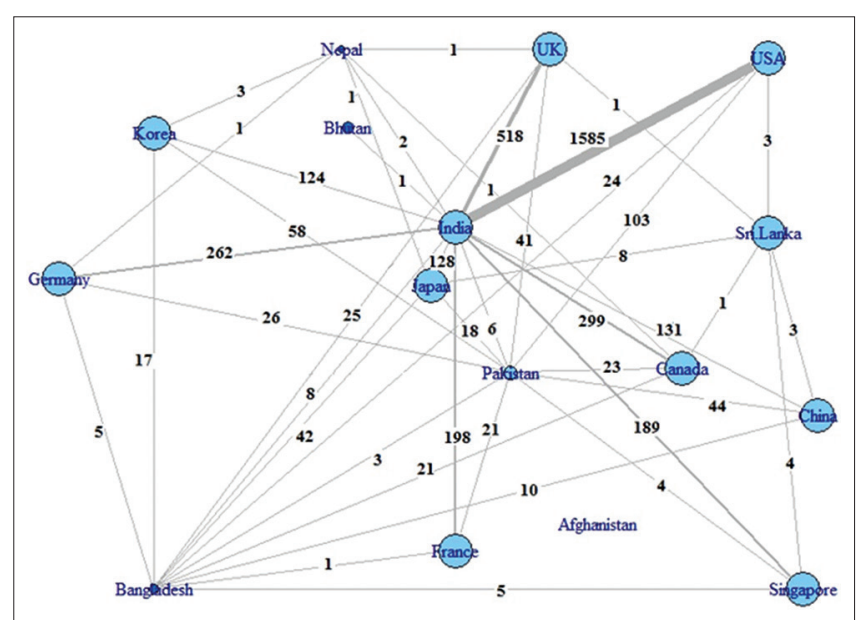

Figure 9: Information technology research collaboration network for South Asian Countries

observe that United States is the biggest collaborating country, amounting to total 1,715 collaborative papers with all South Asian countries, taken together. What is interesting to observe is that each of the South Asian countries have more collaboration with countries outside the South Asian region than the collaboration with a South Asian country. Besides United States, United Kingdom, Germany, Japan, Canada, China, Singapore, Korea, and France; are other leading collaborating partners for IT researchers in South Asian region. Collaboration within South Asian countries is negligible in comparison to collaboration with the outside world. For example, India has only 19 collaborative publications involving countries within South Asia, whereas 1,585 publications have been collaborated with United States alone. The collaboration graph gives the details of ICP pattern for all South Asian countries. The edge weights between two vertices (representing countries) show the collaboration strength between them. A detailed look at the graph tells us that unlike the findings reported in (Schubert and Glänzel, 2006), ${ }^{[5]}$ the South Asian countries have more collaborative output with distant countries than their neighbors. A serious fact finding and corrective action is, therefore, required to find out the reasons for low collaboration levels in IT research among researchers within South Asian countries.

\section{DISCUSSION}

The detailed analysis of IT infrastructure and the IT research in South Asia gives us important and useful inferences. There are several implications for governments as well as other non-state actors in education and research and development field in the South Asian countries. The statistics for tertiary education enrollment, expenditure on higher education and research and development in South Asian countries is far from being at satisfactory level. A lot more emphasis needs to be given on new age knowledge arenas like IT. IT has potential not only for achieving higher development goals but also to transform every field of life for the good. Therefore, higher investment in the IT sector by all the member countries, both on education and research and development, is necessary for the development of the South Asian region. Simply adopting and being consumer of technologies developed in the developed world is not going to be that effective. There is a need of investment in creation and development of original IT products, applications, and services that serve the entire world. This requires effort on various fronts ranging from IT infrastructure growth to higher investment in IT research activities.

When we look at the statistics for penetration levels of Internet and social media in South Asian countries, we realize how much do we lag with the rest of the world. A large part of the population of South Asian countries do not have access to the modern technologies emanating from the IT revolution worldwide. There is a serious digital divide that need to be addressed seriously. Further, whatever reach the IT has in South Asian region is merely in propagating the technologies of the developed world. Most of the websites, electronic platforms in South Asian region continue to be in English, thereby alienating a large number of those people who are educated and able to use the technologies if they have been available in local languages. The Web presence in native languages in these countries is very dismal. Serious effort toward multi-lingual computing technologies is, therefore, very much necessary. The mobile revolution and access to IT services on mobile devices can help a lot in bridging the digital divide. If we pay more attention and commit ourselves toward localization of the technologies and also focus more on creation and development of new products and services, we may be able to progress at a much rapid rate. The youth of the region has potential and ambitions to move forward, and IT can become the desired means to achieve this goal.

Our empirical analysis of the scientometric data on IT research generate very useful inferences and allow us to identify the corrective measures to be taken. We observed that South Asian region, having about $16.5 \%$ of the world population (http://en.wikipedia.org/wiki/South_Asia), contributes only about $2.02 \%$ to the total IT research worldwide. Development and self-sufficiency in IT are not 
possible without higher levels of IT research which produces original algorithms, products, and services. Though, IT is becoming one of the major employment sectors in the South Asian countries, but the major share of the revenue generated goes to companies outside the region. The true potential of our youth can be realized only if we put more conscious effort in IT research activities. The region lags behind the developed world on almost all scientometric indicators. Not only the total IT research output of the region is very low, but also the productivity level (measured as citation impact) is low. The authorship and ICP patterns are also different from the developed world. Some other analytical works ${ }^{[-9-9]}$ on this theme carried out at national or regional levels substantiate our analytical findings. We need to develop the right environment for research and development, including integrated efforts from government and non-government actors. Similarly, a look at collaboration patterns of the South Asian region in IT research is another eye opener. Researchers in South Asian countries collaborate more with researchers in far of countries. We as a region have not been able to put a collective effort and effective systems for higher level and quality of IT research. More programs of joint and collaborative research among the South Asian countries will definitely help in tapping the potential and improving the scenario. With efforts and collective measures toward original research and development, we can develop South Asia as an IT knowledge hub. This will not only impact the national economies for the good but will also help improving the quality-of-life of the individuals in these countries.

\section{REFERENCES}

1. Brown LD, Gardner JC. Using citation analysis to assess the impact of journals and articles on contemporary accounting research (CAR). J Account Res 1985; 23:84-109.

2. Singh VK, Uddin A and Pinto D. Computer Science Research: The Top 100 Institutions in India and in the World. Unpublished work, Under Review in Scientometrics, Springer; 2015.

3. Frenken K, Hölzl W, de Vor F. The citation impact of research collaborations: The case of European biotechnology and applied microbiology (1988-2002). J Eng Technol Manag 2005; 22:9-30.

4. Uddin A, Singh VK. A Quantity-Quality Composite Ranking of Indian Institutions in CS Research. IETE Technical Review, Taylor and Francis; 2015, in press.

5. SchubertA, Glänzel W. Cross-national preference in co-authorship, references and citations. Scientometrics 2006; 69:409-28.

6. Uddin A, Singh VK. Measuring research output and collaboration in South Asian countries. Curr Sci 2014; 107:31-8.

7. Uddin A, Singh VK. Mapping the computer science research in SAARC countries. IETE Tech Rev 2014;31:287-96.

8. Singhal K, Banshal SK, Uddin A, Singh VK. A Scientometric Analysis of the Computer Science Research in India. Proceedings of $1^{\text {st }}$ International Conference on Contemporary Computing and Informatics, Mysore, India, IEEE Xplore; Nov, 2014.

9. Banshal SK, Singhal K, Uddin A, Singh VK. Mapping the Computer Science Research in Bangladesh. Proceedings of the $8^{\text {th }}$ International Conference on Software, Knowledge, Information Management and Applications, Dhaka, Bangladesh, IEEE Xplore; Dec, 2014.

How to cite this article: Singhal K, Banshal SK, Uddin A, Singh VK. The information technology knowledge infrastructure and research in South Asia. J Sci Res 2014;3:134-42.

Source of Support: This work is supported by research grants from Department of Science and Technology, Government of India (Grant: INT/MEXICO/P-13/2012) and University Grants Commission of India (Grant: F. No. 41-624/ 2012(SR)), Conflict of Interest: None declared

\section{Author Help: Reference checking facility}

The manuscript system (www.journalonweb.com) allows the authors to check and verify the accuracy and style of references. The tool checks the references with PubMed as per a predefined style. Authors are encouraged to use this facility, before submitting articles to the journal.

- The style as well as bibliographic elements should be $100 \%$ accurate, to help get the references verified from the system. Even a single spelling error or addition of issue number/month of publication will lead to an error when verifying the reference.

- $\quad$ Example of a correct style Sheahan P, O'leary G, Lee G, Fitzgibbon J. Cystic cervical metastases: Incidence and diagnosis using fine needle aspiration biopsy. Otolaryngol Head Neck Surg 2002;127:294-8.

- Only the references from journals indexed in PubMed will be checked.

- $\quad$ Enter each reference in new line, without a serial number.

- Add up to a maximum of 15 references at a time.

- If the reference is correct for its bibliographic elements and punctuations, it will be shown as CORRECT and a link to the correct article in PubMed will be given.

- If any of the bibliographic elements are missing, incorrect or extra (such as issue number), it will be shown as INCORRECT and link to possible articles in PubMed will be given. 